\title{
Postmastectomy Radiotherapy Decision for Patients without Lymph Node Metastases: Turkish Radiation Oncology Society Breast Cancer Working Group
}

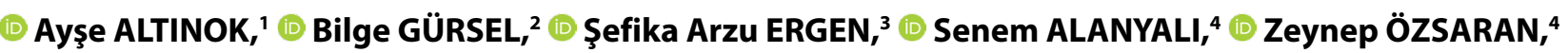 \\ (1) Ayfer AY EREN, ${ }^{5}$ (D) Evrim METCALFE, ${ }^{6}$ (D) Müge AKMANSU,7 (I) Hüseyin TEPETAM, ${ }^{5}$ (D) Pelin ALTINOK, \\ (1) Özgür ALTMIŞDÖRTOĞLU,' @ Alparslan SERARSLAN, ${ }^{2}$ ๑ Nuran BEŞE ${ }^{1}$
}

\begin{abstract}
'Department of Radiation Oncology, 'Acıbadem Maslak Hospital Research Institute of Senology, İstanbul-Turkey
${ }^{2}$ Department of Radiation Oncology, Ondokuz Mayıs University Faculty of Medicine, İstanbul-Turkey

${ }^{3}$ Department of Radiation Oncology, İstanbul University-Cerrahpaşa, Cerrahpaşa Faculty of Medicine, İstanbul-Turkey

${ }^{4}$ Department of Radiation Oncology, Ege University Faculty of Medicine, İstanbul-Turkey

${ }^{5}$ Department of Radiation Oncology, Kartal Dr. Lütfi Kırdar Education and Research Hospital, İstanbul-Turkey

${ }^{6}$ Department of Radiation Oncology, Eskişehir Osmangazi University Faculty of Medicine, İstanbul-Turkey

${ }^{7}$ Department of Radiation Oncology, Gazi University Faculty of Medicine, İstanbul-Turkey

${ }^{8}$ Department of Radiation Oncology, Bezmialem Foundation University Faculty of Medicine, İstanbul-Turkey

${ }^{9}$ Department of Radiation Oncology, Yakın Doğu University Faculty of Medicine, Nicosia, Turkish Republic of Northern Cyprus
\end{abstract}

\begin{abstract}
OBJECTIVE
Recent meta-analysis have not revealed any positive effects of postmastectomy radiotherapy (PMRT) on locoregional recurrence (LRR) or overall survival in axilla-negative patients. However, risk of LRR increases to $15 \%$ in the presence of two or more adverse factors for the same patient group. In this study, PMRT indications and volume selections of radiation oncologists in Turkey for axilla-negative breast cancer was investigated.
\end{abstract}

\section{METHODS}

Questionnaires were distributed to members of the breast cancer study group. Data of patients with axillary negative or isolated/micrometastasis and PMRT over 10 years (2006-2016) were collected from 10 participating centers. Clinical and tumor histopathological features and treatment details of 185 patients were analyzed.

\section{RESULTS}

The median age of patients was 48 years. Ratio of early-stage patients was $60 \%$ (T1-15\%,T2-45\%). There were $147(79 \%)$ negative cases, $32(17 \%)$ with micrometastasis, and $6(3 \%)$ with isolated tumor cells. Half of the patients had only their chest walls (CW) irradiated. Peripheral lymphatics were also included in the rest. In Nmic cases, ratio of irradiation of supraclavicular and axillary lymph nodes with $\mathrm{CW}$ were statistically significant compared to CW irradiation ( $72 \%$ and $28 \%$, respectively; $\mathrm{p}=0.015$ ).

\section{CONCLUSION}

Considering the low number of patients treated over 10 years in 10 different centers in Turkey, it can be said that PMRT is often done in node-negative breast cancer. It is difficult to reach a definite conclusion for patients with Nmic, due to lack of data from patients with PMRT. However, the general tendency is to irradiate peripheral lymphatics in Nmic cases if PMRT is to be performed.

Keywords: Axillary node negative; mastectomy; radiotherapy.

Copyright $\odot$ 2019, Turkish Society for Radiation Oncology

Received: February 04, 2019

Accepted: May 14, 2019

Online: August 20, 2019

Accessible online at:

www.onkder.org

OPEN ACCESS This work is licensed under a Creative Commons

Attribution-NonCommercial 4.0 International License.
Dr. Ayşe ALTINOK,

Acıbadem Maslak Hastanesi Senoloji Araştırma Enstitüsü,

Radyasyon Onkolojisi Anabilim Dalı,

İstanbul-Turkey

E-mail: ayseyildirimaltinok@gmail.com 


\section{Introduction}

Postmastectomy radiotherapy (PMRT) for patients without axillary lymph node metastases is debatable. Retrospective studies and meta-analysis have shown that if there are combined risk factors, the local recurrence risk is up to 20\%.[1-4] On the other hand, Early Breast Cancer Trialists' Collaborative Group's meta-analysis indicates that after complete axillary dissection, PMRT does not have any impact either on local control (LC) or on overall survival (OS) rates. However, patients without lymph node metastases still benefit from PMRT in terms of LC if the axillary approach was just sampling instead of a full dissection.[5-6]

Recently, considering the cosmetic outcome, skinsparing mastectomy (SSM) and nipple areola sparing mastectomies (NSM) have replaced more aggressive surgeries. Although this approach is generally accepted as a safe procedure, some risk factors, such as flap thickness and surgical margin positivity, triple-negative biology, or young age, are considered as adverse factors on LC. [7] Therefore, the decision to treat patients without axillary lymph node metastases with PMRT depends on multiple factors with a tailored treatment approach. If a consensus is difficult to obtain, a questionnaire among practitioners or retrospective evaluation of the characteristics of treated patients might be useful.[8]

Therefore, Turkish Radiation Oncology Society Breast Cancer Working Group designed a study to assess indications of radiation oncologists for PMRT and selection of radiotherapy volumes by retrospectively analyzing the patients without axillary metastases that were treated in Turkey.

\section{Materials and Methods}

Patients who have undergone mastectomy for invasive breast carcinoma and were pathologically diagnosed negative for axillary lymph node metastases and who received radiotherapy between the years 2006 and 2016 were retrospectively evaluated. Additionally, patients with minimal axillary tumor burden such as isolated tumors or micrometastasis in the axillary lymph nodes, determined pathologically, were included in the analysis. A spreadsheet consisting of all patient and tumor characteristics such as age, tumor type, stage, hormone receptor status, histologic grade, lymphovascular invasion (LVI), Ki-67 proliferation index, surgical margin, mastectomy, and axillary surgery type, RT volumes (chest wall, supraclavicular, axillary level 1, 2, 3 and internal mammary lymph nodes), and the total dose and fractionation was prepared. Mastectomy technique is classified into four groups: simple mastectomy, modified radical mastectomy (MRM), SSM and NSM. The surgical assessment of the axilla is divided into two: sentinel lymph node biopsy (SLNB) and axillary dissection.

The approval of ethical committee was obtained. Following the approval and support of the society, the spreadsheet was distributed via email to the members of breast cancer working group of Turkish Society of Radiation Oncology.

We received responses of 13 attendees from 10 different radiation oncology centers. Information on 185 patients was qualified for further analysis. The data on 185 patients were transferred to the SPSS 23 software program (IBM SPSS Statistics for Windows, Version 23.0, Released 2015, IBM Corp. Armonk, NY). Statistical analysis using chi-square, Student $t$ test, and MannWhitney $U$ test were carried out. A p value $<0.05$ was accepted as significant.

\section{Results}

The median age of patients was 48 years (range 22-82 years). Out of 185 patients, 118 (64\%) were premenopausal. In 140 patients $(76 \%)$, the tumor histology was invasive ductal carcinoma. The most frequently used surgical technique was MRM (57\%). Dissection was performed to assess the axilla in 108 patients (58\%); and the median number of dissected lymph nodes was 16 ( $\min .1$, max. 40). (The number of patients with less than 10 dissected lymph nodes was $19(10 \%)$.) The number of sampled lymph nodes with SLNB was 3 (min. 1, max. 7 ) in 77 patients (42\%). Among all patients, 147 (80\%) were node negative.

In $60 \%$ of patients who had undergone PMRT, the tumor stage was detected as T1 (15\%) and T2 (45\%). The ratio of patients with histological grade 2 and grade 3 were $41 \%$ and $47 \%$, respectively. Presence of LVI was found as $50 \%$. The number of patients with triple-negative cancer was 33 (18\%). C-erb2 status was positive in 67 patients $(36 \%)$. Surgical margins were reported as negative in 125 patients (68\%). Patient and tumor characteristics are summarized in Table 1.

A total of $50 \%$ of the patients had chest wall (CW) $\mathrm{RT}$, and $50 \%$ had lymphatic volume irradiation in addition to CW RT. There were 32 patients with micrometastases to axillary lymph nodes; 14 of them underwent axillary dissection (AD) after SLNB (44\%), 
Table 1 Patients and tumor characteristics

\begin{tabular}{|c|c|}
\hline Characteristic & n (\%) \\
\hline \multirow[t]{2}{*}{ Age } & Median \\
\hline & 48.5 (22 min-83 max) \\
\hline \multicolumn{2}{|l|}{ Menopausal status } \\
\hline Premenopausal & $120(65 \%)$ \\
\hline Postmenopausal & 65 (35\%) \\
\hline \multicolumn{2}{|l|}{ Tumor stage } \\
\hline T1 & $28(15 \%)$ \\
\hline $\mathrm{T} 2$ & $84(45 \%)$ \\
\hline T3 & $66(36 \%)$ \\
\hline $\mathrm{T} 4$ & $7(4 \%)$ \\
\hline \multicolumn{2}{|l|}{ Histology } \\
\hline Invasive ductal & $140(76 \%)$ \\
\hline Invasive lobuler & $15(8 \%)$ \\
\hline Other & $30(16 \%)$ \\
\hline \multicolumn{2}{|c|}{ Lymphovascular space involvement } \\
\hline Present & $92(50 \%)$ \\
\hline Absent & $70(38 \%)$ \\
\hline Unknown & $23(12 \%)$ \\
\hline \multicolumn{2}{|l|}{ Grade $(G)$} \\
\hline G1 & $9(5 \%)$ \\
\hline $\mathrm{G} 2$ & $76(41 \%)$ \\
\hline G3 & $87(47 \%)$ \\
\hline Unknown & $13(7 \%)$ \\
\hline Ki 67 & median $30 \%$ \\
\hline$<20 \%$ & $48(26 \%)$ \\
\hline$\geq 20 \%$ & $61(33 \%)$ \\
\hline Unknown & $76(41 \%)$ \\
\hline \multicolumn{2}{|l|}{ Estrogen receptor status } \\
\hline Negative & 72 (39\%) \\
\hline Positive & 109 (59\%) \\
\hline Unknown & $4(2 \%)$ \\
\hline \multicolumn{2}{|l|}{ HER2 status } \\
\hline Negative & $111(60 \%)$ \\
\hline Positive & $67(36 \%)$ \\
\hline Not tested & 7 (4\%) \\
\hline Triple negative & $33(18 \%)$ \\
\hline \multicolumn{2}{|l|}{ Surgery } \\
\hline Simple mastectomy & $59(32 \%)$ \\
\hline MRM & $106(57 \%)$ \\
\hline Skin sparing & $11(6 \%)$ \\
\hline NAC sparing & $9(5 \%)$ \\
\hline \multicolumn{2}{|l|}{ Nodal Status } \\
\hline Negative & $147(79 \%)$ \\
\hline Isolated & $6(3 \%)$ \\
\hline Micrometastasis & $32(17 \%)$ \\
\hline \multicolumn{2}{|l|}{ Surgical Margin } \\
\hline Positive (ink+) & $30(16 \%)$ \\
\hline$<1 \mathrm{~mm}$ & $24(13 \%)$ \\
\hline$<2 \mathrm{~mm}$ & $6(3 \%)$ \\
\hline$>2 \mathrm{~mm}$ & $125(68 \%)$ \\
\hline
\end{tabular}

and only 3 patients without AD (8\%) had CW RT without lymphatic RT. In Nmic patients, the rate of irradiation of level 1, 2, 3 axillary supraclavicular lymph nodes along with $\mathrm{CW}$ was considerably higher than the patients only with CW irradiation $(72 \%$ and $28 \%$ respectively; $\mathrm{p}=0.015$ ).

Six of seven patients (14\%) with tumor stage of $\mathrm{T} 4$ received lymphatic irradiation in addition to $\mathrm{CW}$ $(p=0.07)$. The small number of patients in this group limited further evaluation.

The patients who had undergone NSM significantly received CW RT than lymph volume RT in addition to CW only $(\mathrm{p}=0.013)$.

\section{Discussion}

There is still no consensus regarding the indication and the volume to be irradiated for PMRT of node-negative breast cancer patients. This study aimed to determine the everyday practices of radiation oncologists in Turkey. It was observed that the total number of cases reported from the centers was quite low, and most of the cases had more than one of the adverse factors such as premenopausal status, T2 and T3 stages, grade 3 for PMRT.

In certain guidelines, the existence of the tumor size $>5 \mathrm{~cm}$ was given as the sole indication of PMRT. [9] However, it must be emphasized that tumors reaching these dimensions without lymph node involvement might have unusual biological properties. It has been shown that when these patients do not receive systemic and hormonal therapy after mastectomy, the risk of LR for them is approximately $15 \%$. In the case of chemotherapy and/or hormonal therapy, this risk reduces to $7 \%-8 \%$. Thus, $\mathrm{CW}$ irradiation is not recommended when the only indication is the tumor size being greater than $5 \mathrm{~cm}$ and other adverse factors are absent.[10] However, a recent meta-analysis of PMRT for T3N0 patients presented at American Society of Radiation Oncology 2017 shows that LR decreases with PMRT.[11] In this study, the ratio of T3 patients is $36 \%$. Of these patients, $47 \%$ had grade 3 tumors. The remaining 53\%, who had grade 1 and 2 histopathology, definitely had one or more accompanying adverse factors. T3 stages does not seem to be a sole indicator for PMRT among the practitioners in Turkey.

LVI is also associated with reduced locoregional control and survival in women with node-negative breast cancer treated with mastectomy and systemic therapy.[12] In this study, it was observed that half 
of the patients had a positive LVI status that might have impact on the decision for PMRT. Ki-67 expression also has been shown as an independent factor for DFS and OS in patients with breast cancer.[13] In this study, patients with unknown Ki-67 consisted $41 \%$ of the population. In the remaining, percentage of patients with an increased proliferation index $(\geq 20 \%)$ was higher than the percentage of patients with ki-67 $<20 \%$ (33\% vs. $26 \%$, respectively). The percentage of patients with unknown ki-67 and LVI were quite high that might impacted statistical result (41\% and $12 \%$, respectively).

Triple-negative breast cancer accounts $15 \%-20 \%$ of all breast cancers.[14] Patients with T1-T2N0 TNBC treated with MRM without RT have worse outcome with significant increased risk of LRR.[15] In our study, the number of TN case was 33 (18\%). This ratio is in agreement with other published ratios. This would suggest that tumor biology does not influence PMRT indications of axillary negative cancers.

Furthermore, PMRT indications are not clear for conserving mastectomies, such as SSM and NAC, which might leave residual breast tissue due to cosmetic concerns. Marta et al. conducted a survey study with 292 radiation oncologists. The participants prioritized post SSM and NAC RT criteria as involvement of lymph node, positive of surgical margin, large diameter of tumor, histologic grade 3, LVI, patient age $(<40$ years), multicentric tumor, and triple-negative receptor status. Additionally, PMRT is suggested for NAC cases where flap thicknesses exceeds $5 \mathrm{~mm}$ in the mentioned study as a clinical expert opinion8. In this study, the ratios of SSM and NAC were relatively low. The surgical margin was close to $1 \mathrm{~mm}$ or positive in $60 \%$ of these patients.

Randomized studies have shown that dissection does not have a positive impact in cases with isolated tumor cells or axillary micrometastasis after breast conserving surgery. $[16,17]$ It has been suggested that the low regional recurrence rates in these trials might be due to the partially incidental irradiation of the axilla during whole breast radiotherapy. In the IBCSG 23-01 trial, $9 \%$ of the patients underwent mastectomy, and $19 \%$ had only intraoperative radiotherapy giving $28 \%$ who did not receive incidental axillary irradiation.[18] A prospective randomized study BOOG 2013-07 has evaluated the role of further treatment of axillary in patients with micrometastasis after mastectomy.[19] In the AMAROS trial, the percentage of the patients with micrometastasis or isolated tumor cell was $41 \%$, and all of them received further axillary treatment (either dissection or axillary radiotherapy). [20] Furthermore, in the AMAROS trial, patients received axillary radiotherapy including the contents of all three levels of the axilla and the medial part of the supraclavicular fossa. On the other hand, in a recent study, patients with early-stage tumors (T1-T2) who underwent mastectomy where Nmic involvement is present, CW recurrence rate was found as $2 \%-3 \%$. [21] PMRT does not seem to be effective with so low recurrence rates.

The majority of the local recurrences after mastectomy are on the chest wall.[22] Therefore, CW is accepted as the essential volume for PMRT. Lymphatic volume selection is debatable, and there is no consensus for $\mathrm{pN} 0$ patients. Current study indicates that only tumor stage T4 and Nmic are significant factors for the selection of lymphatic volumes among radiation oncologists, and there is no consensus regarding the selection of lymph nodes as well.

This study is designed just for the indication of PMRT; therefore, locoregional control, disease-free survival, and OS rates were not obtained. The major shortcoming of the current analysis is the lack of information regarding the total number and the features of the N0 or Nmic cases pursuant mastectomy.

\section{Conclusion}

Considering the small number of cases reported for a 10-year period from the major breast centers of Turkey, it has been found that the number of patients with N0 or Nmic who underwent PMRT was not high. The indications depended on the presence of one or more adverse factors (such as premenopausal status, high tumor stage, grade, proliferation index, LVI and biology of the tumor) did not have a significant impact. Regarding PMRT indications of the patients with Nmic, it is difficult to reach a certain conclusion due to the lack of information for those who did not receive radiotherapy. On the other hand, it was observed that comprehensive lymphatic irradiation was preferred after SLNB in the presence of micrometastasis.

Implementation of effective systemic treatments and considerations of the results of recent meta-analysis showing that PMRT does not have any effect on LC and survival rates reduces the number of patients chosen for PMRT.

Peer-review: Externally peer-reviewed.

Conflict of Interest: No conflict of interest. 
Ethics Committee Approval: This study was conducted in accordance with local ethical rules.

Financial Support: None declared.

Authorship contributions: Concept - N.B., A.A.; Design N.B., A.A.; Supervision - N.B.; Materials - A.A., B.G., S..A.E., S.A., Z.Ö., A.A.E., E.M., M.A., H.T., P.A., Ö.A., A.S., N.B.; Data collection \&/or processing - A.A., B.G., Ş.A.E., S.A., Z.Ö., A.A.E., E.M., M.A., H.T., P.A., Ö.A., A.S., N.B.; Analysis and/or interpretation - A.A.; Literature search - A.A., N.B.; Writing - A.A., N.B.; Critical review - N.B.

\section{References}

1. Wallgren A, Bonetti M, Gelber RD, Goldhirsch A, Castiglione-Gertsch M, Holmberg SB, et al. Risk factors for locoregional recurrence among breast cancer patients: results from International Breast Cancer Study Group Trials I through VII. J Clin Oncol 2003;21(7):1205-13.

2. Yildırım E, Berberoğlu U. Can a subgroup of nodenegative breast carcinoma patients with $\mathrm{T} 1-2 \mathrm{tu}-$ mour who may benefit from postmastectomy radiotherapy be identified? Int J Radiat Oncol Biol Phys 2007;68(4):1024-9.

3. Truong PT, Lesperance M, Culhaci A, Kader HA, Speers CH, Olivotto IA. Patient Subsets with T1-T2, Node-Negative Breast Cancer at High Locoregional Recurrence Risk After Mastectomy. Int J Radiat Oncol Biol Phys 2005;62(1):175-82.

4. Rowel N. Radiotherapy to the chest wall following mastectomy for node-negative breast cancer: A systematic review. Radiother Oncol 2009;91(1):23-32.

5. Clarke M, Collins R, Darby S, Davies C, Elphinstone P, Evans V, et al. Effects of radiotherapy and of differences in the extent of surgery for early breast cancer on local recurrence and 15-year survival: an overview of the randomised trials. Lancet 2005;366(9503):2087-106.

6. EBCTCG (Early Breast Cancer Trialists' Collaborative Group), McGale P, Taylor C, Correa C, Cutter D, Duane $\mathrm{F}$, et al. Effect of radiotherapy after mastectomy and axillary surgery on 10-year recurrence and 20year breast cancer mortality: meta-analysis of individual patient data for 8135 women in 22 randomised trials. Lancet 2014;383(9935):2127-35.

7. Headon HL, Kasem A, Mokbel K. The Oncological Safety of Nipple-Sparing Mastectomy: A Systematic Review of the Literature with a Pooled Analysis of 12,358 Procedures. Arch Plast Surg 2016;43(4):32838.

8. Marta GN, Poortmans PM, Buchholz TA, Hijal T. Postoperative Radiation Therapy after Nipple-Sparing or Skin-Sparing Mastectomy: A Survey of European,
North American, and South American Practices. Breast J 2017;23(1):26-33.

9. Truong PT, Olivotto IA, Whelan TJ, Levine M; Steering Committee on Clinical Practice Guidelines for the Care and Treatment of Breast Cancer. Clinical practice guidelines for the care and treatment of breast cancer: 16. Locoregional post-mastectomy radiotherapy. CMAJ 2004;170(8):1263-73.

10. Taghian AG, Jeong JH, Mamounas EP, Parda DS, Deutsch M, Costantino JP, et al. Low locoregional recurrence rate among node-negative breast cancer patients with tumors $5 \mathrm{~cm}$ or larger treated by mastectomy, with or without adjuvant systemic therapy and without radiotherapy: results from five national surgical adjuvant breast and bowel project randomized clinical trials. J Clin Oncol 2006;24(24):392732.

11. Shaikh Jr MP, Alite Jr F, Wu MJ, Altoos T, Jacobson GM. Postmastectomy Radiation Therapy for Node Negative Breast Cancer with Tumor Size of Five Centimeter or More: A Meta-analysis. Int J Radiat Oncol Biol Phys 2017;99(Suppl 2):5.

12. Truong PT, Yong CM, Abnousi F, Lee J, Kader HA, Hayashi A, et al. Lymphovascular invasion is associated with reduced locoregional control and survival in women with node-negative breast cancer treated with mastectomy and systemic therapy. J Am Coll Surg 2005;200(6):912-21.

13. Inwald EC, Klinkhammer-Schalke M, Hofstädter F, Zeman F, Koller M, Gerstenhauer M, et al. Ki-67 is a prognostic parameter in breast cancer patients: results of a large population-based cohort of a cancer registry. Breast Cancer Res Treat 2013;139(2):53952.

14. Boyle P. Triple-negative breast cancer: epidemiological considerations and recommendations. Ann Oncol 2012;23(Suppl 6):7-12.

15. Abdulkarim BS, Cuartero J, Hanson J, Deschênes J, Lesniak D, Sabri S. Increased risk of locoregional recurrence for women with T1-2N0 triple-negative breast cancer treated with modified radical mastectomy without adjuvant radiation therapy compared with breast-conserving therapy. J Clin Oncol 2011;29(21):2852-8.

16. Galimberti V, Cole BF, Viale G, Veronesi P, Vicini E, Intra $\mathrm{M}$, et al. Axillary dissection versus no axillary dissection in patients with breast cancer and sentinelnode micrometastases (IBCSG 23-01): 10-year followup of a randomised, controlled phase 3 trial. Lancet Oncol 2018;19(10):1385-93.

17. Solá M, Alberro JA, Fraile M, Santesteban P, Ramos M, Fabregas R, et al. Complete axillary lymph node dissection versus clinical follow-up in breast cancer patients with sentinel node micrometastasis: final 
results from the multicenter clinical trial AATRM 048/13/2000. Ann Surg Oncol 2013;20(1):120-7.

18. Galimberti V, Cole BF, Zurrida S, Viale G, Luini A, Veronesi P, et al. IBCSG 23-01 randomised controlled trial comparing axillary dissection versus no axillary dissection in patients with sentinel node micrometastases. Lancet Oncol 2013;14(4):297-305.

19. van Roozendaal LM, de Wilt JH, van Dalen T, van der Hage JA, Strobbe LJ, Boersma LJ, et al. The value of completion axillary treatment in sentinel node positive breast cancer patients undergoing a mastectomy: a Dutch randomized controlled multicentre trial (BOOG 2013-07). BMC Cancer 2015;15:610.

20. Donker M, van Tienhoven G, Straver ME, Meijnen P, van de Velde CJ, Mansel RE, et al. Radiotherapy or surgery of the axilla after a positive sentinel node in breast cancer (EORTC 10981-22023 AMAROS): a randomised, multicentre, open-label, phase 3 non-inferiority trial. Lancet Oncol 2014;15(12):1303-10.

21. Mamtani A, Patil S, Stempel M, Morrow M. Axillary Micrometastases and Isolated Tumor Cells Are Not an Indication for Post-mastectomy Radiotherapy in Stage 1 and 2 Breast Cancer. Ann Surg Oncol 2017;24(8):2182-8.

22. Taghian A, Jeong JH, Mamounas E, Anderson S, Bryant J, Deutsch M, et al. Patterns of locoregional failure in patients with operable breast cancer treated by mastectomy and adjuvant chemotherapy with or without tamoxifen and without radiotherapy: results from five National Surgical Adjuvant Breast and Bowel Project randomized clinical trials. J Clin Oncol 2004;22(21):4247-54. 